\title{
A IMPORTÂNCIA DO BRINCAR NO DESENVOLVIMENTO DA CRIANÇA NA EDUCAÇÃO INFANTILE
}

\section{ARTIGO ORIGINAL}

PAVNOSKI, Luciano ${ }^{1}$

PAVNOSKI, Luciano. A importância do brincar no desenvolvimento da criança na educação infantil. Revista Científica Multidisciplinar Núcleo do Conhecimento. Ano 04, Ed. 07, Vol. 09, pp. 49-63. Julho de 2019. ISSN: 2448-0959

\section{RESUMO}

Este trabalho partiu da pretensão em conhecer e estudar a metodologia que os educadores utilizam quando desenvolvem atividades lúdicas na sala de aula com a educação Infantil, visto que a brincadeira tem um papel fundamental, uma vez que estimula o universo interior da criança. Sabendo que, o ensino e a brincadeira andam juntos e é um dos caminhos que possibilita ao educador observar como a criança inicia seu processo de aquisição tanto da linguagem gráfica quanto na forma de expressarse frente a situações do seu cotidiano visto que, os professores exercem um papel admirável no trabalho para que o desenvolvimento da criança seja aprendido gradativamente, respeitando da melhor forma o seu processo de conhecimento. O que dirigiu este trabalho partiu de estudos e observações dos docentes no qual trabalham no mesmo estabelecimento de ensino e que atuam na Educação Infantil. Durante o tempo em que atuo como professor dos anos iniciais do Ensino Fundamental e da educação infantil. Neste período de estudos constantes, constatou-se que os educadores valorizam a atividade lúdica da criança, ou tem a noção do quanto ela é relevante para o processo de conhecimento e desenvolvimento do aluno. O objetivo principal desse estudo foi pesquisar como o professor desenvolve as atividades

\footnotetext{
${ }_{1}$ Pós-Graduado em Educação Infantil - Práticas na Sala de Aula, Pós Graduado em Arte Educação e Terapia, Pós Graduado em Neurociências para Educadores. Graduado em Pedagogia, Graduado em Artes Visuais.
} 
lúdicas na sala de aula da Educação Infantil e conhecer o processo pelo qual o lúdico foi se desenvolvendo na história da humanidade sendo um elemento importante para o ensino de qualidade, e analisando as práticas por eles desenvolvidas nas escolas. O presente estudo se estendeu em três capítulos. No primeiro abordará o lúdico no decorrer da história e a linha de pensamento educacional de importantes autores no que tange o ensino lúdico. O segundo fará uma abordagem através de referenciais bibliográficos sobre a infância e o brincar a relação extraordinária entre as mesmas no processo de ensino na educação infantil e o terceiro destinou-se em descrever e pesquisar como o educador trabalha e pode apresentar suas aulas para que se tornem mais prazerosas introduzindo a brincadeira na sua metodologia de ensino bem como na aula do seu dia a dia.

Palavras chave: professor, criança, brincar.

\section{INTRODUÇÃO}

A ampliação do pensamento das crianças está intimamente relacionada á capacidade de a criança fazer representações para que assim, o pensamento aconteça, é necessário que haja a idoneidade de tornar presente, ou seja, de substituir coisas que até então as crianças não tem contato por meio de palavras e imagens do dia a dia.

A cada figura que a criança representa, o jogo simbólico e o desenho passam a ser uma necessidade do indivíduo, e dessa forma elas vão se colocando no processo de aprendizagem, desde o estágio pré-operatório, onde se inicia o processo de representação, ou seja, começa a se apropriar da escrita como se a mesma fosse um jogo com regras. Assim, nesse processo a escrita deixa de ser uma representação mental para a criança e passa a ser uma representação gráfica, com muitos significados, como no desenho que, primeira passa pela representação mental e em seguida após processos de desenvolvimento passa a representar graficamente.

O espaço escolar deve ser um lugar em que os educandos se sintam acolhidos por todos que fazem parte da comunidade escolar, pois é na Educação Infantil que as crianças estão desenvolvendo suas próprias impressões, idéias e interpretações 
sobre a produção de Arte e o fazer artístico. Essas construções são elaboradas a partir das relações que estas estabelecem com o mundo físico. Dessa forma, as crianças devem receber uma educação de qualidade, contextualizadas na realidade em que vivem e oportunidades educacionais apropriadas que sejam desafiadoras e ajustadas às suas habilidades e necessidades.

O objetivo principal desse estudo foi pesquisar como o professor trabalha o desenho na Educação Infantil, analisando as práticas por ele desenvolvidas nas escolas municipais de Cruzeiro do Iguaçu. Tendo em vista que uma das motivações que levou ao estudo das práticas do ensino do desenho foi o desejo de conhecer e avaliar o trabalho realizado pelos educadores de Arte e, buscando analisar qual o significado que o docente dá para o desenho, esta pesquisa pretende contribuir para que o ensino do desenho na Educação Infantil seja uma forma dos educadores analisarem a importância de realizar atividades significativas para seus educandos, a partir da representação gráfica.

\section{DESENVOLVIMENTO}

\section{O LÚDICO NO DECORRER DA HISTÓRIA}

A etimologia da palavra lúdico origina-se de "ludus" que tem como significado jogo. Desta forma se torna possível compreensão que existe uma referência apenas ao ato jogar, ao divertimento com o caráter "não sério", entretanto mediante estudos, o lúdico deixou de possuir apenas essa conotação de algo não construtivo e passou a ser reconhecido como algo essencial do comportamento humano que traz juntamente com o seu universo, além do divertimento, a possibilidade de aprendizagem em diversos âmbitos na criança.

Diversos autores renomados como Piaget e Vygotsky, Froebel e Dewey, trouxeram o brincar como algo inseparável à natureza humana principalmente da criança quando está no processo de desenvolvimento e que também colabora para o aprendizado, de modo que a definição deixou de ser o simples jogo. Para os autores citados, o brincar e as suas implicações superam o universo do lúdico, possuindo também interferências 
nos âmbitos pedagógicas e sociais, além da brincadeira como um ato de simples prazer.

As atividades lúdicas estão presentes em diversos períodos históricos, desde a Grécia até a Roma antiga, passando pela Idade Média e pelo Renascimento, possuindo em cada período da história características e interpretações diferentes sobre sua importância.

No início do séc. XIX as escolas começaram a trabalhar em seu dia a dia alguns princípios práticos do Froebel e também de Pestalozzi, mas foi Froebel que iniciou os estudos pesquisando para a evolução da criança através do lúdico compreendido como a ação de brincar passando a fazer parte da educação infantil.

A proposta de Froebel para a educação infantil apresentava grande importância do brinquedo e do ato de brincar, contribuindo para a importância das brincadeiras livres trazendo o lúdico como uma essencial ferramenta de trabalho pedagógico do educador.

Segundo Kishimoto (2001, p.14) "Froebel concebeu o brincar como atividade livre e espontânea da criança, e ao mesmo tempo referendou a necessidade de supervisão do professor para os jogos dirigidos apontando questões sempre no contexto atual".

A aprendizagem através do jogo trabalha também as questões sociais e da vida e, estão presentes nesses estudos em que os autores compreendem as atividades lúdicas como ações que estão fortemente ligadas à aprendizagem.

Ainda no campo filosófico Dewey, também contribuiu sobre o lúdico, apresentando que o jogo é uma forma de expressar a atividade espontânea que está na criança, além de ter a capacidade de juntar as necessidades lúdicas com as necessidades para a vida em sociedade ele acredita que a vida social constitui a base do desenvolvimento infantil, e que a escola deve proporcionar a aprendizagem da vida em sociedade. 
Para o referido autor, a educação deve se empenhar para formar a comunicação entre a criança e o seu meio que vive e convive e ainda, segundo ele, o processo de diálogo entre as crianças se dá através do jogo, quando a criança começa e se habituar às regras existentes e, conseqüentemente, com as que irá encontrar no decorrer da sua vida em sociedade.

Dessa forma em seus estudos referentes à Dewey, Amaral afirma:

Aprender é uma necessidade orgânica, é social para a criança, por que tanto seus poderes devem ser traduzidos em seus equivalentes sociais, como o objetivo deve permitir através de sua conotação fortemente socializadora, a manifestação orgânica potencial da criança (AMARAL, 2008 p.103).

No séc. XX abre-se espaço para o crescimento da psicologia infantil, com estudos que debatem 0 ato de brincar para a construção na vida da criança e assim, Piaget e Vygotsky apresentam novos pressupostos sobre o lúdico e aprendizagem infantil.

Para Piaget as crianças participam ativamente do seu desenvolvimento durante o dia a dia e enquanto estão no espaço de educação infantil na sala de aula e, é depois do desenvolvimento que surge a aprendizagem.

Os jogos têm como objetivo o divertimento, mas caracterizam-se também pelos movimentos realizados com o próprio corpo durante um exercício de dança ou outro realizado.

Após o aparecimento da linguagem a criança inicia os jogos simbólicos entre os 2 aos 6 anos caracterizando-se de ( pré-operatório) onde a criança pode brincar e participar com jogos de imitação ou até mesmo de ficção é a partir dessas atividades a criança se aproxima da realidade e assimila situações nela presentes, como afirma Friedman (1996, p.29): “(...) No jogo simbólico a criança se interessa pelas realidades simbolizadas, e o símbolo serve somente para evocá-las." 
O jogo simbólico é uma transformação de objetos que a criança tem e visualiza no seu dia a dia e que está em contato em símbolos. Dentre as suas funções destacamse a realização de desejos, liquidação de conflitos e a compensação, este tipo de jogo tem como principal característica a do período pré-operatório onde, a criança utiliza a representação de um objeto através de outro.

A criança tem o jogo como uma atividade fundamental para o aprendizado e seu desenvolvimento não só escolar, mas para o conhecimento de mundo.

Vygotsky também desenvolveu estudos relacionados ao lúdico e sua relação com a aprendizagem segundo suas pesquisas, no momento em que a criança participa do exercício lúdico é que as aprendizagens se dão de maneira mais clara. Quando as crianças brincam com situações imaginárias existem também as representações de situações reais, para Vygotsky todas as situações que a criança vive servem de elementos para a sua imaginação, ela observa, vive, cria e recria as situações, fato que faz com que ela aprenda de acordo com o que conhece em seu meio.

Após leituras compreende-se que Piaget e como Vygotsky vêem a criança como aquela que recria realidades e transformam situações vividas, embora que, para Piaget o desenvolvimento se inicie com a maturação biológica e para Vygotsky é proporcionado pela interação com o meio social que vive.

O exercício lúdico pode ser visto como uma expressão de entendimento, para as pessoas que já possuem estruturas cognitivas formadas, o meio mais comum de comunicação utilizada é a linguagem verbal, estando assim, as crianças num nível de desenvolvimento cognitivo em que elas ainda não dispõem da linguagem para se comunicar e é através das brincadeiras que elas se comunicam e manifestam seus pensamentos e sentimentos. Assim torna-se possível perceber que o jogo não é algo original na vida do ser humano e que suas mediações tanto no desenvolvimento quanto na aprendizagem já vinham sendo estudadas e que trazem a brincadeira como elemento inseparável à vida infantil. 


\section{O BRINCAR NA INFÂNCIA DA CRIANÇA}

O significado de criança possui aspectos diversos se entendermos a sociedade atual a qual somos participantes e também com cada período histórico a qual já passamos.

Ao conceituar a criança e a infância podemos citar que essa construção faz parte de um processo onde, primeiramente tem toda uma associação com o contexto, regras e valores impostos pelas pessoas e outro que traz as visões dos adultos com relação as suas memórias de tempo vivido, ou seja, o entendimento de infância acaba por ter em seu conteúdo uma visão talvez fantasiada do passado, mas, em consonância com a visão da sociedade. A criança não é, e não pode ser vista como um adulto, ela ainda precisa dar-se por diversas fases de desenvolvimento, entre eles está o desenvolvimento motor, físico, entre outros, para chegar à fase adulta e, a brincadeira lúdica é um dos elementos necessários para o seu bom desenvolvimento.

Conforme já foi visto, as atividades lúdicas é algo inseparável ao ser humano e que está presente em sua vida, principalmente, durante a infância. Qualquer ação exercida pela criança pode ser considerada uma brincadeira, não há pesquisas que determinam quais as formas de agir podem ser consideradas e interpretadas como uma atividade lúdica infantil. Para identificar se a ação realizada é uma brincadeira, basta que os sujeitos envolvidos na atividade lúdica a motivem dessa forma. Todo jogo e toda a brincadeira pressupõe uma cultura específica que pode ser denominada cultura lúdica, um conjunto de procedimentos que tornam a ação do jogo do brincar e a atuação dos que brincam possíveis.

Kishimoto (2008 p.24 á 27) afirma que:

"Dispor de uma cultura lúdica é dispor de um número de referências que permitem interpretar como jogo atividades que poderiam não ser vistas como tal para outras pessoas. O desenvolvimento da criança determina as experiências possíveis, mas não produz por si só a cultura lúdica. Esta se origina das interações sociais (...)". 
O jogo implica um ponto de partida que chamamos de cultura lúdica, é essa cultura que irá determinar o caminho a ser percorrido da brincadeira.

No momento em que a criança domina essa cultura, ela participa e brinca envolvendose nas formas diferenciadas de brincar, sobretudo as brincadeiras de faz-de-conta quando a mesma cria uma situação imaginária que é vivenciada e posteriormente trazida para a sua realidade.

Quando a criança da início a construção do faz-de-conta ela passa a utilizar e definir outras funções para os objetos do seu meio além daquelas que se percebe durante a brincadeira. Esse processo de construção da brincadeira e da imaginação traz para a criança resultados importante para o seu desenvolvimento, já que há muitas vezes simulação de ações em que materiais são utilizados por ela para significar outro conforme pensamento da criança que o determina e, durante as brincadeiras de fazde-conta a criança acaba por utilizar em alguns momentos elementos presentes do seu dia a dia e que tem mais contato, ela utiliza como matéria prima de sua imaginação o que foi observado e vivenciado durante diversos momentos em sua vida tanto em casa quanto em outro local onde a mesma está .

Como Cerisara afirma:

Quando a criança brinca, ela cria uma situação imaginária, sendo esta uma característica definidora do brinquedo em geral. Nesta situação imaginária, ao assumir um papel a criança inicialmente imita o comportamento do adulto tal como ele observa em seu contexto (CERISARA, 2008, p.130).

A ação do brincar não é a utilização somente de elementos imaginários, pode-se também concordar situações reais vivenciadas com outras do universo da imaginação entre elas estão às experiências vividas com idéias virtuais através do contato que as crianças têm com as redes sociais.

De acordo com Brougére (1995, p. 32) 
(...) a brincadeira pode ser vista como uma forma de interpretação que a criança fez e faz sobre o brinquedo, ele não condiciona as ações da criança, mas oferece um suporte que poderá ganhar inúmeros significados a partir do imaginário e de acordo como o decorrer da brincadeira acontece.

Todo o trabalho pedagógico realizado pelo professor em sala de aula deve priorizar o desenvolvimento e a aprendizagem da criança. É por ela, pelo seu desenvolvimento integral que devemos planejar nossas ações nas escolas de educação infantil.

A criança é um sujeito histórico e de direitos que se desenvolve através das interações, das brincadeiras, das práticas educativas, das relações e práticas cotidianas que the são disponibilizadas na escola ou fora do espaço educativo. Logo, cabe ao adulto, ao professor, disponibilizar um grande acervo cultural, um bom repertório educativo para que as crianças de diferentes grupos sociais e contextos culturais a que pertencem, possam ter a garantia de uma educação de qualidade.

Se a criança é a nossa preferência, se ela é de fato o centro das nossas preocupações, necessita-se acompanhar a mesma em cada canto de cada escola, se às crianças está assegurado o direito de brincar, de aprender, de interagir, de dialogar, de observar e experimentar, de questionar, de aprender, de explorar os sentidos, de ouvir e acompanhar histórias, de desenhar e representar o que está apreendendo, de aprender a respeitar as diferenças entre outros elementos importantes no processo de desenvolvimento. Como as novas Diretrizes Curriculares Nacionais da Educação Básica, MEC (2009), comenta: [...] o conhecimento científico hoje disponível autoriza a visão de que desde o nascimento a criança busca atribuir significado a sua experiência e nesse processo volta-se para conhecer o mundo material e social, ampliando gradativamente o campo de sua curiosidade e inquietações, mediadas pelas orientações, materiais, espaços e tempos que organizam as situações de aprendizagem e pelas explicações e significados a que ela tem acesso (MEC, 2009. p. 06) 
O período de vida no qual a Educação Infantil caracteriza-se é de profundas aquisições: a marcha, a fala, a formação da imaginação e da capacidade de fazer de conta e de representar usando diferentes linguagens.

Para entendermos as aquisições que as crianças fazem no proceder dos anos da educação infantil, é preciso ressaltar que consideramos o processo de aprendizagem fundamental nas escolas para o estabelecimento do desenvolvimento infantil.

Segundo Vygotsky, a aprendizagem ocorre na interação com outras pessoas, o que nos possibilita o avanço no desenvolvimento psicológico. As escolas infantis que atendem crianças de 0 a 5 anos têm importante função no desenvolvimento infantil das crianças, pois, muitas vezes, elas passam boa parte do tempo nesse espaço e é nele que irá experimentar as sensações do mundo e desenvolver suas habilidades.

Diversos estudos apontam que é através do brincar que a criança terá a garantia da aprendizagem. Segundo Vygotsky (1998), o brinquedo e a brincadeira influenciarão o desenvolvimento das crianças.

O brincar espontâneo, livre, nas brincadeiras grupais, com uso de brinquedos ou não, é considerado brincar no momento do desenvolvimento da brincadeira, quando há uma predominância das circunstâncias imaginárias, e quando ocorrem transformações internas no desenvolvimento da criança que surgem por meio das brincadeiras e brinquedos.

\section{A IMPORTÂNCIA DA PRÁTICA DO EDUCADOR NAS ATIVIDADES LÚDICAS NA EDUCAÇÃO INFANTIL}

O processo da educação infantil no Brasil, correspondente a creches e pré-escolas. Esta modalidade escolar passou a integrar a educação básica brasileira a partir de 1996, quando a Lei n 9394/96 Lei de diretrizes e bases da educação - LDB, entra em vigor.

Após dez anos, em fevereiro de 2006, a lei 11.274 é praticada fazendo algumas alterações na LDB, a respeito à educação básica e aos seus níveis de ensino. 
Portanto, de acordo com a nova lei do ensino fundamental de nove anos, não caberia mais a educação infantil atender às crianças com seis anos de idade, e assim, estas foram implantadas no primeiro ano do ensino fundamental. Dessa forma, a educação infantil hoje, é composta pelas creches, responsáveis pelas crianças de até 3 anos e pré-escola com as crianças de 4 e 5 anos.

Recordando sobre as atividades lúdicas, é um tanto que faz parte da natureza humana e que é direito da criança constando no Art. 16 do Estatuto da Criança e do Adolescente - ECA e que este define o lúdico como um dos direitos de liberdade da criança e ainda, leva em importância que uma parte do seu dia a criança está inserida na escola, para que esse seu direito seja garantido, a escola deve ser um dos ambientes onde a brincadeira deve acontecer.

O Referencial Curricular Nacional para Educação Infantil traz em seu texto diversos tópicos que devem ser acatados por uma escola de educação infantil e o lúdico deve fazer arte entre eles. Assim:

Considerando-se as especificidades afetivas, emocionais, sociais e cognitivas das crianças de zero a seis anos, a qualidade das experiências oferecidas que podem contribuir para o exercício da cidadania devem estar embasadas nos seguintes princípios: o respeito à dignidade e aos direitos das crianças, consideradas nas suas diferenças individuais, sociais, econômicas, culturais, étnicas, religiosas etc.; o direito das crianças a brincar, como forma particular de expressão, pensamento, interação e comunicação infantil; o acesso das crianças aos bens socioculturais disponíveis, ampliando o desenvolvimento das capacidades relativas à expressão, à comunicação, à interação social, ao pensamento, à ética e à estética; a socialização das crianças por meio de sua participação e inserção nas mais diversificadas práticas sociais, sem discriminação de espécie alguma; o atendimento aos cuidados essenciais associados à sobrevivência e ao desenvolvimento de sua identidade (BRASIL, 1998, p.13). 
As escolas de educação infantil precisam ser vistas como um local que beneficia o desenvolvimento infantil em seus diversos significados, e o referencial da Educação Infantil ao considerar a brincadeira como uma das questões mais importantes e presentes durante a vivência das crianças, já assinala a importância dessa ação para o desenvolvimento e para o aprendizado do aluno.

O espaço para brincá-lo dentro da escola através da inserção do lúdico nas propostas pedagógicas da escola permite o desenvolvimento infantil, principalmente, quando se trata da questão do imaginário, e recria no momento em que o aluno brinca proporcionando novas vivências e através desta, decorrência do desenvolvimento.

Quando o lúdico tem finalidade pedagógica na escola de educação infantil é importante ressaltar o grande valor existente nesses materiais e no processo de desenvolvimento da criança bem como na sua aprendizagem.

Como afirma Kishimoto:

Ao permitir à ação intencional (afetividade), a construção de representações mentais (cognição), a manipulação de objetos e o desempenho de ações sensório motor (físico) e as trocas e interações, o jogo contempla várias formas de representação da criança ou suas múltiplas inteligências, contribuindo para a aprendizagem e o desenvolvimento infantil (KISHIMOTO, 1996, p.39).

Ao adquirir o papel de atividade lúdica, o brinquedo precisa ter características: a colocação lúdica quando o mesmo irá propiciar a diversão e a colocação educativa, quando a brincadeira tem em seus objetivos ensinar qualquer coisa que acrescente a criança conhecimento e desenvolvimento. Também é importante compreender que além da brincadeira educativa direcionada, o aprendizado também existe quando acontece a brincadeira livre, ou seja, aquela em que a criança determina o início, o andamento e as regras conforme seu gosto.

No momento em que o educador utiliza um brinquedo na sala de aula ele pode possibilitar inúmeras aprendizagens, inclusive muitas além da qual ele foi direcionado 
lembrando que, nessa ocorrência varia de criança para criança. $O$ fato é que embora o lúdico proporcione uma riqueza de situações de aprendizagem, não é provável ter a certeza de que a construção do conhecimento tencionada pelo professor será realizada pelo aluno.

Utilizar-se de jogos, ajuda na motivação da criança e, acaba por potencializar o trabalho pedagógico que o professor almeja fazer e também estimula o desenvolvimento da criança, contribuindo para que ocorra uma aprendizagem prazerosa e significativa.

A brincadeira quando aplicada à prática do educador no espaço de sala de aula, contribui para a aprendizagem dos alunos e assim, permite que o professor seja mais dinâmico e criativo em suas aulas ao mesmo tempo em que a criança sinta prazer em participar das atividades escolares oferecidas.

Assim, podemos dizer que o lúdico é um recurso pedagógico e deve ser usado da melhor forma, pois, o verdadeiro sentido da educação lúdica está na preparação do professor ao aplicá-lo corretamente (ALMEIDA, 2004, p32).

O educador tem papel indispensável, é o de intervir de forma correta quando necessário e, deixando que a criança adquira novos conhecimentos e habilidades durante processos de exercícios lúdicos, já que a importância da inclusão e utilização dos brinquedos, jogos e brincadeiras na prática pedagógica é uma realidade que se atribui ao professor.

Brinquedos não devem ser utilizados somente para descanso, mas também como elementos que enriquecem a aprendizagem. Para isso, o professor precisa estar ciente de que a brincadeira para a criança é indispensável e que ela traz grandes contribuições no desenvolvimento das habilidades de aprender.

E Almeida (2004, p. 14) afirma que: 
Quanto mais o adulto vivenciar sua ludicidade maior será a chance de este profissional trabalhar com a criança de forma prazerosa. Desta maneira, o jogo e a brincadeira são experiências vivenciais prazerosas. Assim a experiência da aprendizagem tende a se constituir em um processo vivenciado de forma prazerosa.

A escola como espaço importante na valorização e na educação, ao apreciar as atividades lúdicas, ajuda a criança a formar um apropriado conceito de mundo, em que a afetividade é acolhida, a sociabilidade vivenciada, a criatividade estimulada e os direitos da criança respeitados.

A formação lúdica que o professor difere através de suas aulas valoriza a criatividade e a busca da afetividade na criança e o adulto, ou seja, os pais que vivenciam essas atividades em casa em "alguns casos" revivem e com prazer a alegria do brincar.

Quando refletem sobre as possibilidades de possível intervenção e de ensino com a utilização do lúdico, os professores sempre relatam experiências em que estão presentes sentimentos e posicionamentos que demonstram a relação entre educador e educando dentro da sala de aula.

Neste ponto de vista, se o professor souber observar as perguntas que seus alunos fazem, a maneira como descobrem objetos e brinquedos, ele irá compreender que existem diversas possibilidades de intervenção durante as atividades pedagógicas desenvolvidas por ele na sala de aula, pois a brincadeira como uma prática pedagógica exige conhecimento e pesquisa por parte do professor (FEIJó, 1992).

É importante que o educador dentro da sala de aula, descubra e trabalhe a importância lúdica que existe em sua essência, no seu trajeto cultural, de forma a aperfeiçoar a sua prática, pois o lúdico é uma necessidade básica da personalidade, do corpo e da imaginação e faz parte das atividades dinâmica humana.

A brincadeira poderia ser a ponte facilitadora da aprendizagem se o professor pudesse pensar e questionar sobre sua forma de ensinar, relacionando a utilização do lúdico como fator determinante de qualquer tipo de aula. No entanto, para que isso aconteça 
é necessário que busque resgatar a ludicidade, os momentos lúdicos que com certeza permearam seu caminho (FEIJÓ, 1992).

É importante destacar que as alternativas pedagógicas, ao serem utilizadas, devem ser devidamente planejadas pelos educadores. Porém, o professor não deve usar os jogos sem que haja um cuidadoso planejamento, marcado por etapas muito claras e que efetivamente acompanham o progresso dos alunos.

No planejar de uma atividade, o educador deve antes apropriar o tipo de jogo ao seu público e o conteúdo a ser trabalhado, para que os resultados através do jogo lúdico utilizado como meio com fins pedagógicos de ensino sejam aceitáveis e os objetivos alcançados.

O lúdico como um recurso pedagógico importante e significativo podem revelar para os alunos e esses perceberem suas próprias capacidades e dificuldades. Portanto, compete ao professor identificar tais competências, de forma a propiciar a integração de todas as áreas de desenvolvimento e aprendizagem dos alunos.

E é através da explicação de Fernández (2001) que podemos fazer uma relação entre a aprendizagem e o brincar de maneira cativante. Fernández (2001) ainda diz que a palavra aprender quer dizer, apropriar-se da linguagem, recordar o passado para despertar-se ao futuro, deixar-se surpreender pelo já conhecido, reconhecer-se e admitir-se.

Mas isso só é possível quando professores provocarem espaços de brincar-aprender para seus alunos ou quando, de forma simultânea, construir para si mesmos. Assim, dentro deste ponto de vista, o lúdico é um importante recurso pedagógico para a definição de ações pedagógicas adequadas a serem estudadas em cursos de formação de professores. 


\section{CONCLUSÃO}

O trabalho que se realiza com as crianças pequenas, é muito delicado por ser o início da vida escolar das crianças e que a partir desse contato, a escola e educador exercer papel importante também na formação das crianças.

A educação infantil não é apenas a formação inicial da criança ela, vai muito além do que apenas a aplicação de conteúdos importantes para o pleno desenvolvimento do aluno. A Educação Infantil preparar para as diversas situações da vida da criança e a escola é um dos ambientes que deve proporcionar essa abertura.

É as atividades lúdicas que as crianças desenvolvem a imaginação e assim vão descobrindo de forma gradativa as diferentes possibilidades existentes e a realidade que está contida, aprendendo de maneira correta a tomar as suas próprias iniciativas.

Frente ás pesquisas, leituras e descrições contidas neste trabalho, pode-se concluir que é de suma importância decorrer sobre as inúmeras possibilidades e grandezas no desenvolvimento da criança que os jogos e as brincadeiras lúdicas realizadas na sala de aula fazem, pois esses são considerados atividades elevadas de interação e construção do conhecimento da realidade vivenciada pelas crianças.

O ambiente escolar, é um ambiente social e, deve ser para todos os envolvidos no processo educativo professores, pais e comunidade no geral, um lugar para a troca de vivências e de experiências.

Os educadores se comprometem e ajudam no crescimento da criança de acordo com o nível de desenvolvimento, durante as aulas, oferecendo um ambiente de qualidade que estimule as interações sociais, um ambiente enriquecedor de imaginação com disponibilidade de diferentes jogos pedagógicos ajudando no processo de aprendizagem do alunado.

Além disso, as diferentes brincadeiras e possibilidades de jogos, esses são indispensáveis na escola para que assim, haja uma aprendizagem significativa e que 
desperte o prazer no ato do trabalho do educador e que facilite as práticas pedagógicas em sala de aula.

Quanto a atenção na preparação das atividades para a educação infantil, é importante que os profissionais estejam devidamente preparados para que não haja um desligamento das atividades pedagógicas pois, essas atividades precisam ser escolhidas com cuidado, seguindo um processo de reconhecimento e conhecimento das turmas, do nível de desenvolvimento intelectual, físico e emocional de cada aluno para não acontecer a aplicação da atividade apenas como um cumprimento de obrigações.

\section{REFERÊNCIAS BIBLIOGRÁFICAS}

ALMEIDA, Paulo Nunes de. Educação lúdica: técnicas e jogos pedagógicos. São Paulo, SP: Loyola, 2004.

AMARAL, Maria Nazaré de Camargo Pacheco. Dewey: jogo e filosofia da experiência dramática. In: . O brincar e suas teorias. São Paulo: Pioneira

Thomson Learning, 2008.

ALMEIDA, FERNÁNDEZ, Regina, 0 jogo facilita a aprendizagem. $3^{\circ}$. Ed. São Paulo: Editora 2001.

BRASIL. Ministério da Educação e do Desporto. Secretaria de Educação Fundamental. Referencial Curricular para a Educação Infantil: Brincar. Brasília: MEC / SEF, 1998. Documento Introdutório.

BROUGÈRE, G. Brinquedo e cultura. Tradução de Maria Alice de Sampaio Dória. São Paulo: Cortez, 1995. 110p.

CERISARA, Ana Beatriz. Educar e Cuidar: por onde anda a educação infantil? Perspectiva. Florianópolis, n. especial, p. 07-10, jul./dez. 1999. Disponível em: http://www.uel.br/ceca/pedagogia/pages/arquivos/ELIZANGELA\%20BUENO.pdf. 
DEWEY, J. Como Pensamos. São Paulo, Companhia Editora Nacional, 1952.

FEIJÓ, O. G. - Corpo e Movimento. Rio de Janeiro: Shape, 1992.

FRIEDMAN, Adriana. Brincar, crescer e aprender - 0 resgate do jogo infantil. São Paulo: Moderna, 1996.

FROEBEL, Friedrich. 0 formador de crianças pequenas. Série Grandes pensadores. Nova Escola. São Paulo: Abril. Disponível em: $<$ http://revistaescola.abril.com.br >

KISHIMOTO, T.M.. Jogos Infantis: o jogo, a criança e a educação. Petrópolis: RJ: Vozes, 1993.

o jogo e a educação infantil. São Paulo: Pioneira, 1994.

KISHIMOTO, Tizuco (org.). Jogo, brinquedo, brincadeira e educação. São Paulo: Cortez, 1996.

KISHIMOTO, Tizuko Morchida (Org.). Jogo, brinquedo, brincadeira e a educação. 5. Ed. São Paulo: Cortez, 2001.

KISHIMOTO, Tizuko Morchida (org.). Jogo, brinquedo, brincadeira e a educação. 11. Ed. São Paulo, Cortez, 2008.

PIAGET, J. A Construção do real na criança. Rio de janeiro, Zahar, 1970 A representação do mundo na criança. Rio de janeiro, Zahar, 1971. Petrópolis, Vozes, 1973.

PIAGET, J. A formação do Símbolo na criança. Rio de Janeiro, Zahar, 1976 (a).

VYGOTSKI, L.S. A formação social da mente. 4. Ed., São Paulo: Martins Fontes, 1991.

VYGOTSKI, L.S. A formação social da mente. 6. Ed., São Paulo: Martins Fontes, 1998. 
Enviado: Abril, 2019.

Aprovado: Julho, 2019. 